\title{
Editorial
}

\section{Licence to Publish - Authors in the British Journal of Nutrition Now Retain the Copyright of their Material}

It is a truism to say that it is a time of great change in academic publishing. The number of specialist journals continues to increase and direct web publishing is developing rapidly. It is now also the norm for long-established paper-based journals such as the $B J N$ to be available online at the same time as the printed version. PubMed Central, which proposes to make journal articles (and perhaps nonpeer reviewed material) freely available on the web was launched in February of this year with the Proceedings of the National Academy of Sciences and Molecular Biology of the Cell being the first journals to appear. PubMed Central (http://www.pubmedcentral.nih.gov/) may ultimately evolve to be a single, searchable site for the free access to all bioscience articles, as originally envisaged by Harold Varmus. A similar development has been discussed in Europe with E-Biosci expected to be up and running later this year; commercial publishers, aware of the threat to their activities, are now actively involved in this development.

One of the other key areas of change in academic publishing lies in the question of copyright, in particular who should own it. The traditional approach has been for journals, whether from a commercial publisher or from a learned society, to insist on authors ceding the copyright to them. The central arguments in favour of this approach have been that a single organisation (the publisher) is better placed to protect copyright than individual authors, and the requirement for copyright transfer has been viewed as a reflection of the investment that the publisher has made in the publication process. Attitudes are changing rapidly, however, and this is partly driven by the extent to which the academic world has embraced the concept of intellectual property rights. A growing number of authors have felt that the balance is tipped too much in favour of the journals and their publishers - rather than the authors who are the originators of the work.

The $B J N$ is in the vanguard of changing attitudes to copyright ownership, and I am delighted to announce that as of July $1^{\text {st }}$ authors (or their institutions) will now retain copyright on all their material that we publish. What we now ask is for an exclusive 'Licence to Publish'. This will provide the $B J N$, and the Nutrition Society, with the essence of what is needed; namely that we, and only we, publish a particular piece of work in its entirety. For authors there will be a greater sense of ownership and control over their material. They will, for example, be able to reproduce part of their work, including figures, in another context such as a review without having to gain permission from us (we do, however, require an acknowledgement of the original source). Authors will also be able to legitimately make multiple copies of their work for non-commercial purposes, such as for teaching. Posting a paper on a personal web page, or on that of the home institution, will also be entirely at the author's discretion.

In making this move we hope that our authors - past, present and future - will feel that we are making a positive development in their favour. At one level this is a further reason why nutritional scientists, and those in allied fields, should consider submitting their best work to the $B J N$; I believe that the full retention of copyright should be a significant added attraction to an author.

The $B J N$ is not alone in these developments. A similar move is underway with the other Nutrition Society journals (Nutrition Research Reviews, Proceedings of the Nutrition Society and Public Health Nutrition). The British Medical Journal and the associated BMJ Publishing Group have moved to a Licence to Publish as of January of this year (Editorial, 2000). The $B J N$ is much indebted to the Association of Learned and Professional Society Publishers who have considered the issue of copyright at length and developed a model licence. Our own licence, which is reproduced on the preceding page, is based on that produced by the Association (who themselves no longer require the transfer of copyright from an author for their own journal, Learned Publishing).

Authors are asked to submit the completed Licence to Publish at the same time as the initial submission of their manuscript. The Licence will be printed in the January and July issues of the $B J N$ each year, i.e. at the beginning of a volume. It is also available on the Nutrition Society's web pages (http://www.nutsoc.org.uk/) from where it can be downloaded as a PDF file. The latest version of the full 'Directions to Contributors' are posted on the web pages and authors are advised to consult these rather than the printed version. In the near future we expect to publish only the concise version of the 'Directions' in the BJN (inside the cover of each issue) with the full 'Directions' being available exclusively on the web site.

The Licence to Publish and the growing use of the web are part of the continuing development of the $B J N$. Access to the journal is now available both from the Nutrition Society's home pages and via Ingenta (http://www.ingenta. com/), as well as from CABI Publishing. Other recent changes include the availability of colour plates, the first example of which was published in the March issue (vol. 83, no. 3) of this year. On a more personal note, readers will see that our position as a genuinely international journal is now such that for the first time the office of Editor-in-Chief is no longer based in the United Kingdom. 
Paul Trayhurn

Editor-in-Chief, British Journal of Nutrition Institute for Nutrition Research, University of Oslo P.O. Box 1046 Blindern,

\section{Reference}

Editorial (2000) Giving something back to authors. British Medical Journal 320, 6. 